\title{
Synthesis and Properties of Syndiotactic Graft Copolymer of Styrene with Polyisoprene Macromonomer by $\mathrm{CpTiCl}_{3}-$ Methylaluminoxane Catalyst
}

\author{
Kiyoshi $\mathrm{EnDO}^{\dagger}$ and Kazunobu SENOO \\ Department of Applied Chemistry, Faculty of Engineering, Osaka City University, \\ Sugimoto, Sumiyoshi-ku, Osaka 558-8585, Japan
}

(Received January 21, 1999)

\begin{abstract}
Copolymerization of styrene with styrene-terminated polyisoprene macromonomer (SIPM) by titanium compounds in combination with methylaluminoxane (MAO) was investigated. SIPM having high end functionality and narrow molecular weight distribution was prepared by reaction of the living polyisoprene initiated with sec-butyllithium ( $s$-BuLi) and p-chloromethyl styrene. $\mathrm{CpTiCl}_{3}-\mathrm{MAO}$ catalyst $(\mathrm{Cp}$ : cyclopentadienyl) was found an effective catalyst for the synthesis of well-defined syndiotactic graft copolymer. The amount of incorporated SIPM in the graft copolymer could be controlled by the SIPM charged. The melting point of the syndiotactic graft copolymers decreased with increasing the number of SIPM per molecules.
\end{abstract}

KEY WORDS Syndiotactic Graft Copolymer / Polyisoprene Macromonomer / Metallocene Catalyst /

Long Chain Branch / Graft Chain Content /

Since the discovery of syndiotactic polystyrene (SPS) by Ishihara et al,, much effort has been focused on the syndiospecific polymerization of $\mathrm{St}$ and its derivatives using homogeneous catalysts consisting of titanium compounds in combination with methylaluminoxane (MAO). ${ }^{1-10}$ SPS has superior physical properties such as a high melting temperature and a fast rate of crystallization, so that the changing such properties by copolymerization is interesting.

Using the metallocene catalysts has an advantage for not only the synthesis of stereoregular polymers but also copolymerization using higher olefins such as the 1-hexene and 1-octene. ${ }^{11}$ Many works have been published on the synthesis of the long-chain branched polyethylene and polypropylene with various metallocene catalysts. ${ }^{12-24}$ However, little attention has been paid to copolymerization of styrene and its derivatives having long side chains using stereospecific catalysts. ${ }^{25,26}$

To prepare graft copolymers with a well-defined side chain structures, the macromonomer technique is very useful, because the macromonomer with the controlled molecular weight and narrow molecular weight distribution can be obtained by the living system. ${ }^{27,28}$ Synthesis of the graft copolymers using the macromonomer methods has also an advantage for the study of blending between polystyrene and polyisoprene. Since the polyisoprene macromonomer is immiscible to the polystyrene, the obtained graft copolymer will be useful for investigation of micro-phase separated structures and ordering of the copolymer. ${ }^{29}$ The polymers increased flexibility and processibility by incorporating a small amount of higher olefins because of drastic decrease in crystallinity. ${ }^{30}$ Many graft copolymers were synthesized by copolymerizations of macromonomers with unsaturated monomers through radical, ${ }^{31}$ anionic, ${ }^{32}$ and cationic polymerizations. ${ }^{33}$ However, it is generally difficult to synthesize stereoregular graft copolymers on the main chain by such polymerizations.

Previously, we reported the syndiotactic copolymeriza-

\footnotetext{
$\uparrow$ To whom correspondence should be addressed.
}

tion of St and styrene-terminated polyisoprene macromonomer with titanium compounds in combination with MAO. ${ }^{34}$ This article describes the effects of the catalysts and side chain length on the copolymerization of styrene with styrene-terminated polyisoprene macromonomer. Thermal properties of the graft copolymers are discussed.

\section{EXPERIMENTAL}

\section{Materials}

Commercial grade monomers and solvents were purified by conventional methods. sec-Butyllithium ( $s$-BuLi in cyclohexane), Cp*TiCl $3, \mathrm{Cp} * \mathrm{Ti}\left(\mathrm{OCH}_{3}\right)_{3}, \mathrm{CpTiCl}_{3}$ (Aldrich Chem.), and methylaluminoxane (MAO) in toluene (Tosoh-Akzo Chem.) were used as received.

\section{Synthesis of the SIPM and Copolymerization with $S t$}

The synthesis of the styrene-terminated polyisoprene macromonomer (SIPM) is illustrated in Scheme 1. ${ }^{32,34}$ After the reaction, the solution was poured into a large amount of methanol to precipitate the macromonomer formed, and the product was isolated and dried in vacuum. The yield was determined by gravimetry. Copolymerization of St and the SIPM was carried out in a glass tube in toluene. The resulting polymer was extracted by methyl ethyl ketone (MEK) for $12 \mathrm{~h}$ at $80^{\circ} \mathrm{C}$.

\section{Characterization}

${ }^{1} \mathrm{H}$ and ${ }^{13} \mathrm{C}$ NMR spectra of the SIPM and MEKinsoluble part of the polymer were measured in $\mathrm{CDCl}_{3}$ at $30^{\circ} \mathrm{C}$ and $o$-dichlorobenzene $/ \mathrm{C}_{6} \mathrm{D}_{6}$ at $120^{\circ} \mathrm{C}$ using JEOL A-400 spectrometer. Number average molecular weights of the polymers $\left(M_{n}\right)$ were determined by vapor pressure osmometry (VPO) using a Knauer Vapor Pressure Osmometer at $40^{\circ} \mathrm{C}$ and molecular weight distribution $\left(M_{w} / M_{n}\right)$ was estimated by GPC using Tosoh GPC-8000 series at $38^{\circ} \mathrm{C}$ in tetrahydrofuran (THF) as calibrated with standards polystyrenes. GPC data for the MEK-insoluble fraction were obtained from Waters GPC $150 \mathrm{CV}$ at $120^{\circ} \mathrm{C}$ in $o$-dichlorobenzene. The glass 


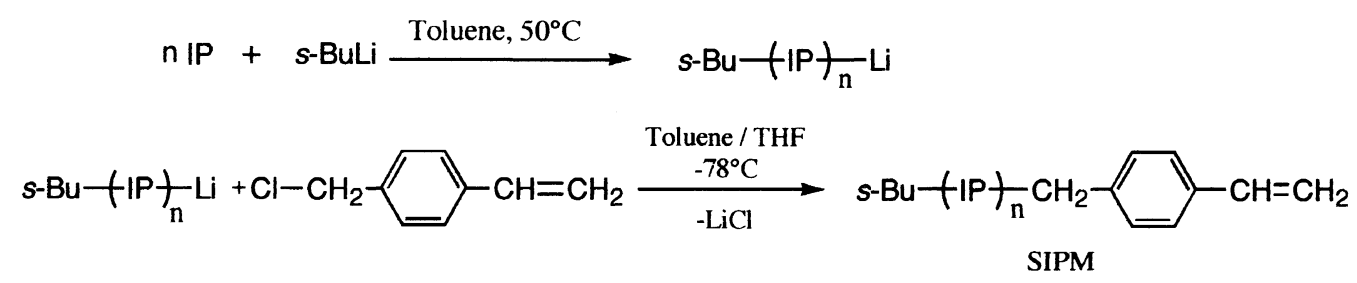

Scheme 1. Synthesis of the SIPM.

Table I. Synthesis of SIPM macromonomer by living anionic polymerization ${ }^{\mathrm{a}}$

\begin{tabular}{|c|c|c|c|c|c|c|c|c|}
\hline \multirow{2}{*}{ Entry } & \multicolumn{2}{|c|}{ Molecular weight } & \multirow{2}{*}{$\begin{array}{l}M_{n} \cdot M_{n} \\
(\mathrm{GPC})\end{array}$} & \multirow{2}{*}{$P_{n}{ }^{\mathrm{b}}$} & \multirow{2}{*}{$f^{\mathrm{c}}$} & \multicolumn{3}{|c|}{ Microstructure $/ \%$} \\
\hline & (VPO) & (NMR) & & & & cis $-1,4$ & trans-1,4 & 3,4 \\
\hline SIPM-1 & 1300 & 1340 & 1.14 & 17 & 0.97 & 68.4 & 20.9 & 10.7 \\
\hline SIPM-2 & 1920 & 2000 & 1.14 & 26 & 0.96 & 64.9 & 25.7 & 9.4 \\
\hline SIPM-3 & 3000 & 3050 & 1.13 & 41 & 0.98 & 66.1 & 23.6 & 10.3 \\
\hline
\end{tabular}

a Polymerization were carried out for $3 \mathrm{~h}$ at $50^{\circ} \mathrm{C}$ and terminated reactions were carried out for $12 \mathrm{~h}$ at $-78^{\circ} \mathrm{C}$ in toluene/THF solvent mixture, $[\mathrm{IP}]=1.0 \mathrm{~mol} \mathrm{dm}^{-3} .{ }^{\mathrm{b}}$ Degree of polymerization. ${ }^{\mathrm{c}} \omega$-End group functionality, $(f)$ were estimated by comparing molecular weights determined from the peak intensity ratio of the methyl proton to those of vinyl proton and that determined by VPO. ${ }^{\mathrm{d}}$ Determined by ${ }^{1} \mathrm{H}$ NMR.

transition temperature $\left(T_{\mathrm{g}}\right)$ and melting point $\left(T_{\mathrm{m}}\right)$ of the graft copolymers were measured by differential scanning calorimetry (DSC) using SEIKO, S II EXSTAR 6000 thermal analyzer at a heating rate of $10^{\circ} \mathrm{C} \mathrm{min}^{-1}$.

\section{RESULTS AND DISCUSSION}

\section{Synthesis of the SIPM}

Degree of polymerization $\left(P_{n}\right)$ can be controlled by varying the mole ratio of the isoprene monomer to the $s$-BuLi initiator in feed. SIPM having different $P_{n}$ thus obtained are listed in Table I. From a comparison of GPC elution curves for synthesized SIPM and controlled polyisoprene terminated by adding methanol to the living polyisoprene, it is clear that no side reactions such as dimerization and polymerization of the SIPM with $p$ chloromethyl styrene ( $p$-CMS) leading to decrease of functionality occurred during the reaction. Terminal functionality of SIPM was estimated from the ${ }^{1} \mathrm{H}$ NMR peak intensity ratio of methylene protons of the terminal vinyl group and methyl protons of polyisoprene and $M_{n}$ of the reaction product estimated from VPO measurement. The incorporation of terminal styryl unit was almost complete $(98 \%)$ regardless of molecular weight.

\section{Copolymerization of St and the SIPM}

The results of the copolymerization of St with SIPM are shown in Table II. The copolymerization of St and SIPM proceeded readily by titanium compounds-MAO catalysts giving powdered products in high yields, although catalytic activity was sensitive to the titanocene compounds examined. The structure of MEK-insoluble fraction of the graft copolymer was confirmed by ${ }^{13} \mathrm{C}$ and ${ }^{1} \mathrm{H}$ NMR spectroscopy to be the graft copolymer having a high syndiotacticity of the main chain and well-defined polyisoprene of the side chain as described previously. ${ }^{34}$ From Table II, the electron-withdrawing chloro ligands of the half metallocene are favorable to produce syndiotactic polymers. The bulky substituents decreased catalytic activity for the copolymerization. Thus, it is clear that the $\mathrm{CpTiCl}_{3}$ catalyst is the most
Table II. Copolymerization of SIPM ${ }^{\mathrm{a}}$ and St with Titanium compound-MAO catalysts in toluene at $50 \mathrm{C}$ for $3 \mathrm{~h}^{\mathrm{b}}$

\begin{tabular}{|c|c|c|c|c|}
\hline \multirow{2}{*}{$\begin{array}{l}\text { Titanium } \\
\text { compound }\end{array}$} & {$[\mathrm{St}]$} & {$[\mathrm{Ti}]$} & Yield $^{c}$ & MEK insol. \\
\hline & $\mathrm{mol} \mathrm{L}^{-1}$ & $\mathrm{mmol} \mathrm{L}^{-1}$ & $\%$ & $w t \%$ \\
\hline $\mathrm{CpTiCl}_{3}$ & 2.9 & 0.31 & 52.8 & 73.0 \\
\hline $\mathrm{Cp} * \mathrm{TiCl}_{3}$ & 2.9 & 0.46 & 19.9 & 27.5 \\
\hline $\mathrm{Cp} * \mathrm{Ti}(\mathrm{OMe})_{3}$ & 2.9 & 0.46 & 18.2 & 11.9 \\
\hline
\end{tabular}

a SIPM: $M_{n}=2400, M_{w} / M_{n}=1.14 . \quad{ }^{\mathrm{b}}[\mathrm{SIPM}]=50 \mathrm{~g} \mathrm{dm}^{-3},[\mathrm{MAO}]$ $[\mathrm{Ti}]=500 .{ }^{\mathrm{c}}$ Include unreacted SIPM.

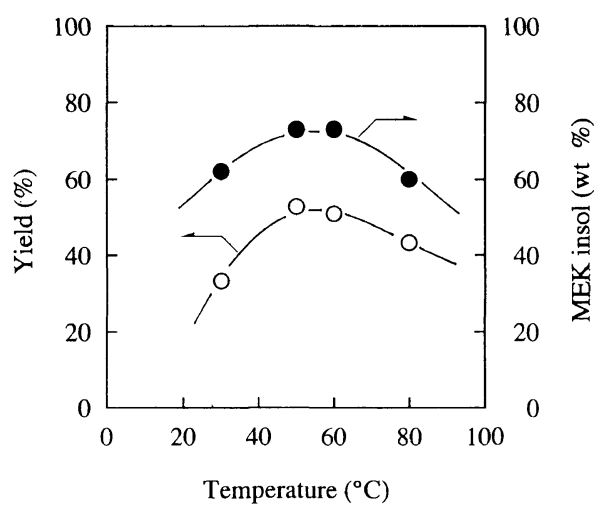

Figure 1. Effects of reaction temperature on the yields and MEK insoluble parts of copolymers from the copolymerization of St with the SIPM by $\mathrm{CpTiCl}_{3} / \mathrm{MAO}$ catalyst.

suitable for the syndiotactic copolymerization of St and the SIPM.

From the GPC profile of MEK-insoluble fraction and MEK-soluble fraction obtained with the $\mathrm{CpTiCl}_{3} / \mathrm{MAO}$ catalyst, the elution curve of MEK-insoluble fraction shifted to a higher molecular weight side as compared with the macromonomer and it did not contain unreacted SIPM. The MEK-soluble fraction contained unreacted SIPM and only a small amount of atactic graft copolymer.

Figure 1 shows the effects of reaction temperatures on 
crude yields and MEK-insoluble fractions of the resulting polymers for the copolymerization of St with the SIPM by the $\mathrm{CpTiCl}_{3} / \mathrm{MAO}$ catalyst. Polymer yield and amount of $\mathrm{MEK}$-insoluble fraction depended on reaction temperature, and optimum temperature was $50^{\circ} \mathrm{C}$, which is consistent with the reported results for the syndiospecific polymerization of St with the same catalyst. ${ }^{2}$

Figure 2 shows the effects of the MAO/Ti mole ratio on polymer yields of syndiotactic graft copolymers. The yield of syndiotactic graft copolymer increased with $\mathrm{MAO} / \mathrm{Ti}$ mole ratio up to 500 , but the molecular weight decreased. Above an $\mathrm{MAO} / \mathrm{Ti}$ mole ratio of 500 , the copolymer yield did not depend remarkably on the MAO/Ti molar ratio. ${ }^{2}$

\section{SIPM Incorporation into the Graft Copolymer}

To elucidate the effects of the molecular weights of the SIPM on the graft chain contents and graft copolymer yields, the copolymerization of St and different molecular weights SIPM with the $\mathrm{CpTiCl}_{3} / \mathrm{MAO}$ catalyst was

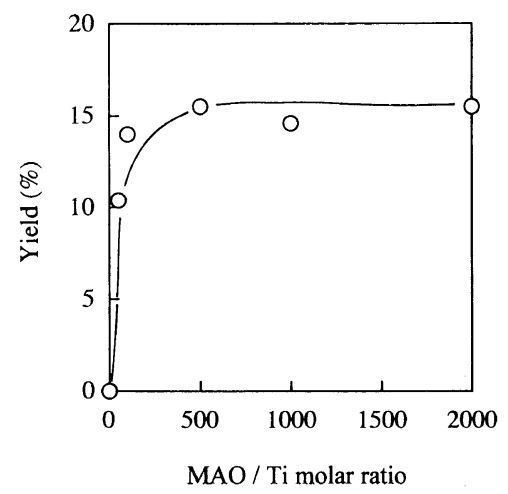

Figure 2. Effects of $\mathrm{MAO} / \mathrm{Ti}$ molar ratio on polymer yields of syndiotactic graft copolymer, $[\mathrm{St}]=2.7 \mathrm{~mol} \mathrm{~L}^{-1},[\mathrm{SIPM}]=50 \mathrm{~g} \mathrm{~L}^{-1}$, and $[\mathrm{Ti}]=0.46 \mathrm{mmol} \mathrm{L}^{-1}$.

Table III. Effects of molecular weight of SIPM on the number of grafts per molecule ${ }^{a}$

\begin{tabular}{|c|c|c|c|c|}
\hline \multirow{2}{*}{$\begin{array}{c}\text { SIPM } \\
\text { molecular } \\
\text { weight }\end{array}$} & $\begin{array}{c}\text { PIPb } \\
\text { content }\end{array}$ & \multirow{2}{*}{$\begin{array}{c}\mathrm{GPC}^{\mathrm{c}} \\
M_{w} \times 10^{-4}\end{array}$} & \multirow{2}{*}{$\begin{array}{l}\text { Number of } \\
\text { grafts per } \\
\text { molecule }\end{array}$} & \multirow{2}{*}{$\begin{array}{c}\text { SPS sequence } \\
\text { length } \\
M_{w} \times 10^{-4}\end{array}$} \\
\hline & $w t \%$ & & & \\
\hline 1300 & 7.8 & 6.48 & 3.9 & 1.53 \\
\hline 1920 & 12.8 & 2.40 & 1.6 & 1.31 \\
\hline 3000 & 23.5 & 2.15 & 1.7 & 0.97 \\
\hline
\end{tabular}

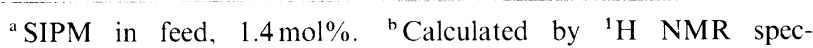
trum. 'Determined from high temperature GPC. carried out. The number of grafts per molecule was calculated from peak intensity of the methylene protons of polyisoprene and methylene protons of polystyrene by the ${ }^{1} \mathrm{H}$ NMR spectra and the results are listed in Table III. Although the number of the grafts per molecules did not change significantly in the graft copolymers obtained at the same mole of the SIPM in feed, yield and molecular weight of the syndiotactic graft copolymer were found to depend strongly on the chain length of the SIPM. The longer chain of the SIPM appeared to hinder the propagation reaction of styrene.

The effects of the amount of the SIPM in the comonomer feed on graft chain contents and the graft copolymer yields were also examined. The results are shown in Table IV. Although the molecular weight of the graft copolymer decreased as a function of SIPM in the feed, the graft chain contents and number of graft chains per molecule increased with SIPM in the feed. The number of graft chains was estimated as 0 to 2.0 and depended on the graft chain contents as is clear shown in Figure 3.

We estimated the monomer reactivity ratio of St $\left(\mathrm{M}_{1}\right)$ and SIPM $\left(\mathrm{M}_{2}\right)$ on the basis of the copolymerization equation 1 with data at low conversion. The conventional Mayo-Lewis equations reduced to eq 1 when the mole ratio in the feed is very large so that $\left[\mathrm{M}_{1}\right] \gg\left[\mathrm{M}_{2}\right]$. $^{35}$

$$
\begin{aligned}
-\mathrm{d} & {\left[\mathrm{M}_{1}\right] /-\mathrm{d}\left[\mathrm{M}_{2}\right] } \\
& =\left(1+r_{1}\left[\mathrm{M}_{1}\right] /\left[\mathrm{M}_{2}\right]\right) /\left(1+r_{2}\left[\mathrm{M}_{2}\right] /\left[\mathrm{M}_{1}\right]\right) \\
& \left.=r_{1}\left[\mathrm{M}_{1}\right] /\left[\mathrm{M}_{2}\right]\right)
\end{aligned}
$$

The reactivity ratio of styrene $\left(r_{1}\right)$ was calculated using the observed mole ratio of styrene to SIPM in the graft copolymer and that in feed, based on the $P_{n}=26$ of the macromonomer determined by ${ }^{1} \mathrm{H}$ NMR spectrum. $r_{1}$ of styrene thus obtained was estimated to be 2.44. Since the mole concentration of the SIPM is much smaller than that of styrene, the exact $r_{2}$ value is difficult to determine. Thus, $1 / r_{1}$ was used to study the copolymerization reactivity of the SIPM. ${ }^{36} 1 / r_{1}$ was 0.41 , smaller than that of the corresponding small monomer $\left(1 / r_{1}=2.0\right)$ calculated from the syndiotactic copolymerization of styrene $\left(\mathrm{M}_{1}\right)$ with $p$-methyl styrene $\left(\mathrm{M}_{2}\right) \cdot{ }^{37,38}$ We suggest that the decrease of the copolymerization reactivity of the SIPM might be affected by the stiffness in the syndiotactic main chain in addition to the incompatibility between the polystyrene segment in the main chain and the polyisoprene segment in the side chain.

Table IV. Properties of graft copolymers with SPS backbone and PIP grafts

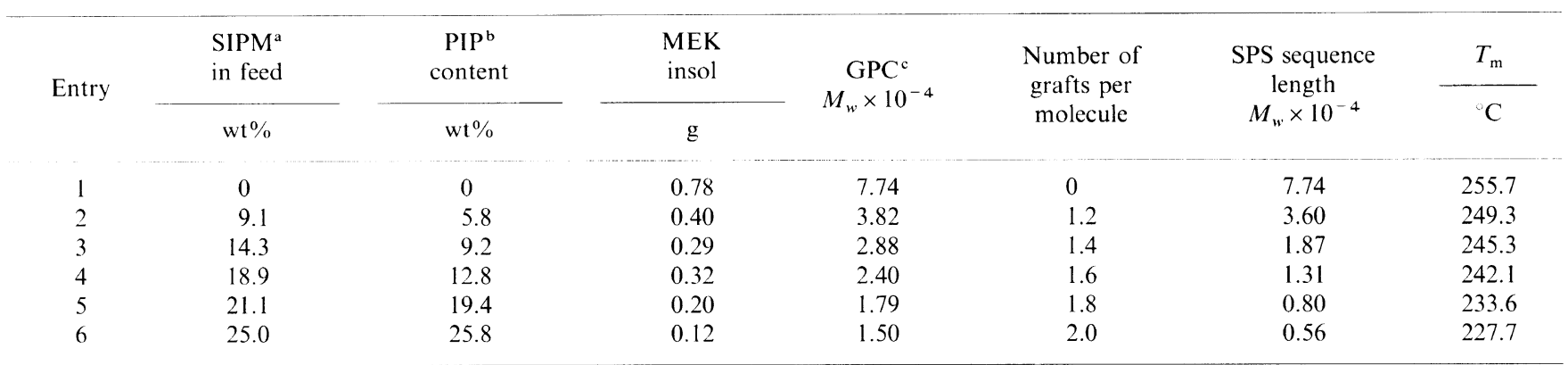

a SIPM: $M_{n}=1920$ (VPO). $\quad{ }^{\mathrm{b}}$ Calculated by ${ }^{1} \mathrm{H}$ NMR spectrum. $\quad{ }^{\mathrm{c}}$ Determined by GPC. 

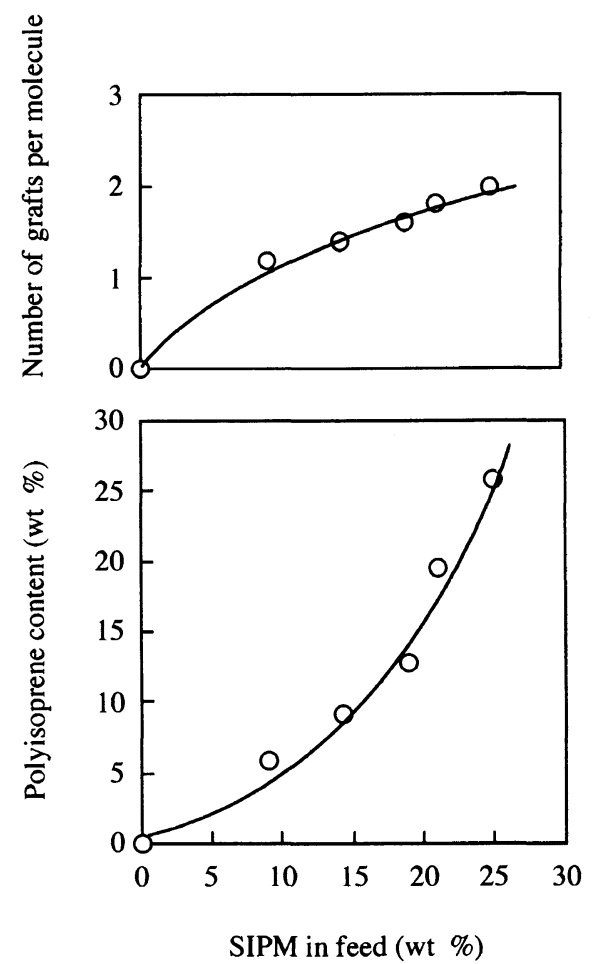

Figure 3. Relationship between graft chain content of the graft copolymer and SIPM in the comonomer feed.

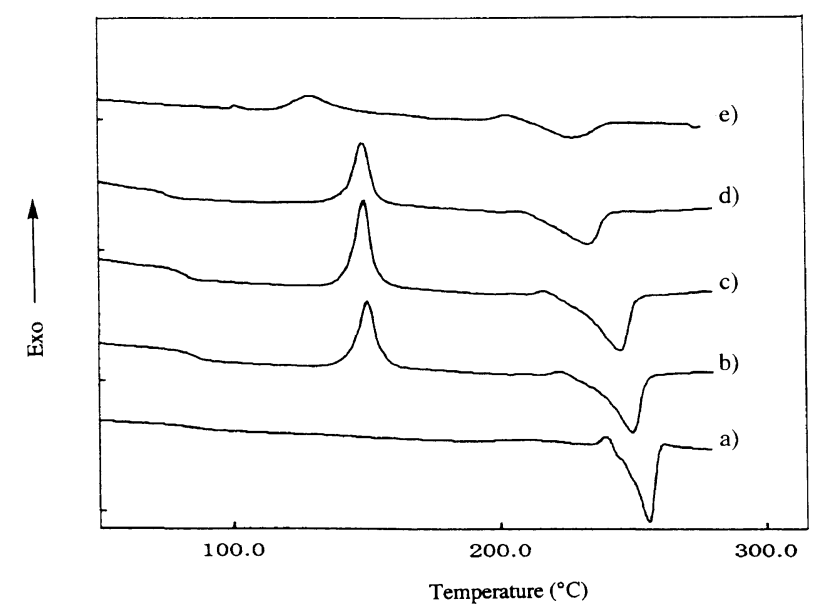

Figure 4. DSC curves of the graft copolymer with a polyisoprene content of a) $0 \mathrm{wt} \%$, b) $5.8 \mathrm{wt} \%$, c) $9.2 \mathrm{wt} \%$, d) $14.7 \mathrm{wt} \%$, and e) $36.7 \mathrm{wt} \%$

\section{Thermal Behavior of the Graft Copolymer}

DSC curves of the syndiotactic graft copolymers with different macromonomer contents are shown in Figure 4. All samples were preheated to $270^{\circ} \mathrm{C}$ to provide a consistent thermal history. The single melting point $\left(T_{\mathrm{m}}\right)$ and glass transition temperature $\left(T_{\mathrm{g}}\right)$ were observed for all graft copolymers examined. $T_{\mathrm{m}}$ and crystallinity of the graft copolymers decreased with increase of the graft chain contents. The long branch chain introduced by copolymerization with the polyisoprene macromonomer may thus disturb the crystallinity of the syndiotactic polystyrene. Henschke et al. reported that the crystallinity of graft copolymers was influenced by the average length of main chain sequences between two grafts in the copolymer backbone. ${ }^{24}$ The length in the syndiotactic main chain of the graft copolymer decreased from $77.4 \times 10^{3}$ to $5.6 \times 10^{3}$ with increasing graft chain content. This great reduction caused decrease of crystallinity of the graft copolymer. The glass transition temperature of the main chain is lowered with the reduction of the average length of the main chain sequences due to greater graft chain content.

\section{CONCLUSIONS}

A graft copolymer consisting of highly syndiotactic polystyrene of the main chain and polyisoprene of the graft chain was obtained by the copolymerization of SIPM produced by a living anionic polymerization with styrene by $\mathrm{CpTICl}_{3} / \mathrm{MAO}$ catalyst. The incorporated SIPM in the graft copolymer depended on the amount of SIPM. The thermal properties of the syndiotactic graft copolymers were strongly influenced by grafting polyisoprene content.

Acknowledgment. This study was partially supported by a Grant-in-Aid for Scientific Research (B) (2540/ 10450356) from the Ministry of Education, Science, Sports and Culture of Japan.

\section{REFERENCES}

1. N. Ishihara, T. Seimiya, M Kuramoto, and M. Uoi, Macromolecules, 19, 2464 (1986).

2. N. Ishihara, M Kuramoto, and M. Uoi, Eur. Pat. Appl., 210625 (1987) to Idemitsu Kosan Co., Chem. Abstr., 106 (1987).

3. N. Ishihara, M Kuramoto, and M. Uoi, Macromolecules, 21, 3356 (1988).

4. A. Zambelli, P. Longo, C. Pellecchia, and A. Grassi, Macromolecules, 20, 20351 (1987).

5. K. Soga, C. H. Yu, and T. Shiono, Makromol. Chem. Rapid Commun., 9, 351 (1988).

6. J. C. W. Chien, Z. Salajka, and S. Dong, Macromolecules, 25, 3199 (1992).

7. W. Kaminsky and S. Lenk, Macromol. Symp., 118, 45 (1997)

8. R. Po and N. Cardi, Prog. Polym. Sci., 21, 47 (1996).

9. T. H. Newman and M. T. Malàmga, Pure Appl. Chem., A34, 1921 (1997).

10. B. Wuderlich, "Macromol. Physics," Vol. 3, 1st ed, Academic Press, New York, N.Y., 1988.

11. M. J. Schneider, R. Mülhaupt, and H. H. Brintzinger, Macromolecules, 30, 3164 (1997).

12. A. Malmberg and J. V. Seppälä, Macromolecules, 31, 8448 (1998)

13. W. J. Wang, D. Yan, S. Zhu, and A. E. Hamielec, Macromolecules, 31, 8677 (1998).

14. A. S. Mehta, C. S. Speed, J. A. N. Canich, N. Baron, B. J. Folie, M. Sugawara, A. Watanabe, and H. C. Welborn, Exxon Chemicals, Int. Patent WO 96/12744.

15. S. Y. Lai, J. R. Wilson, G. W. Knight, J. C. Stevens, and P. W. S. Chum, Dow Chemical Company, U. S. Patent 5,272,236.

16. P. Howard, P. J. Maddox, and S. R. Partington, B P Chemicals Ltd., EP0676 421 Al.

17. J. M. Carella, Macromolecules, 29, 8280 (1996).

18. J. F. Vega, A. Muñoz-Escalona, A. Santamaria, M. E. Muñoz, and P. Lafuente, Macromolecules, 29, 960 (1996).

19. A. E. Hamielec and J. B. P. Soares, Prog. Polym. Sci., 21, 651 (1996).

20. M. Kakugo, Macromol. Symp., 89, 545 (1995).

21. N. Naga, K. Mizunuma, H. Sadatoshi, and M. Kakugo, Macromolecules, 30, 2197 (1997).

22. T. Shiono, Y. Moriki, and K. Soga, Macromol. Symp., 97, 161 (1995)

23. T. Shiono, Y. Moriki, T. Ikada, and K. Soga, Macromol Chem. Phys., 198, 3229 (1997). 
24. O. Henschke, A. Neubauer, and M. Arnold, Macromolecules, 26, 8097 (1997).

25. R. Thomann, F. G. Sernetz, J. Heinemann, and J. Kressler, Macromolecules, 30, 8401 (1997).

26. P. Longo, A. Proto, P. Oliva, I. Sessa, and A. Zambelli., J. Polym. Sci., Part A, Polym. Chem., 35, 2697 (1997).

27. K. Ito, Prog. Polym. Sci., 23, 581 (1998).

28. Y. Tsukahara, "Polymeric Materials Encyclopedia," Vol. 6, J. C, Salamone, Ed., CRC Press, Boca Raton, FL, 1996, p 3918.

29. N. Sakamoto and T. Hashimoto, Macromolecules, 31, 8493 (1998).

30. M. Arnold, S. Bornemann, F. Köller, T. J. Menke, and J. Kressler, Macromol. Chem. Phys., 199, 2647 (1998).

31. T. Otsu, K. Yamashita, and K. Tsuda, Macromolecules, 19, 2219 (1986).

32. R. Asami, M. Takaki, and H. Hanahata, Macromolecules, 16
628 (1983).

33. T. Higashimura, M. Sawamoto, and S. Aoshima, Makromol. Chem. Macromol. Symp., 13/14, 513 (1988).

34. K. Endo and K. Senoo, Macromol. Rapid. Commun., 19, 563 (1998).

35. M. K. Mishra, "Macromolecular Design; Concept and Practice," Polymer Frontiers International, Inc., New York, N.Y., 1994, p 161.

36. K. Ito, Y. Masuda, T. Shintani, T. Kitano, and Y. Yamashita, Polvm. J., 15, 443 (1983)

37. Y. Yamashita, "Chemistry and Industry of Macromonomers," IPC, Tokyo, 1989.

38. H. Nakatani, K. Nitta, K. Soga, and T. Tanaka, Polymer, 38 4751 (1997). 